\title{
DESIGN EVALUATION AND OPTIMIZATION OF STEERING YOKE OF AN AUTOMOBILE
}

\author{
S.K. Chandole ${ }^{1}$, M.K. Bhavsar ${ }^{2}$, S.S. Sarode ${ }^{3}$, G.R. Jadhav ${ }^{4}$ \\ ${ }^{1}$ Assistant Professor, Mechanical Engineering, Late G.N.S COE Anjneri, Nasik, Maharashtra, India \\ ${ }^{2} P G$ Scholar, Mechanical Engineering, Amrutvahini COE Sangamner, Ahmednagar, Maharashtra, India \\ ${ }^{3}$ Assistant Professor, Mechanical Engineering, Late G.N.S COE Anjneri, Nasik, Maharashtra, India \\ ${ }^{4}$ PG Scholar, Mechanical Engineering, Late G.N.S COE Anjneri, Nasik, Maharashtra, India
}

\begin{abstract}
The purpose of a steering system is to control the direction of the vehicle by operating the steering wheel of the steering system. The steering columns in a steering system are one of the main devices of an automobile. It is a very important part to attain stability and steady movement of the vehicle. The steering yoke consists of two forged-steel yokes or forks joined to the two shafts being coupled and situated at right angles to each other. A spider hinges these two yokes together. Since the arms of the spider are at right angles the spider arm rocks backwards and forward between four extreme positions. Motion transmission system of vehicles consist several components which sometimes encounter unfortunate failures. Some common reasons for the failures may be manufacturing, design faults, maintenance faults, raw material faults, material processing faults as well as the user originated faults.

In this paper structural optimization of the steering yoke is carried out. For modeling of the component, CATIA V5 R17 software is used. It has been found that there are essentially in two stages of the design process that structural optimization can be applied. In the early stage of concept generation, topology optimization should be used to develop an efficient structure from the beginning. At this level an automatized variation of optimization parameters was proven useful to and the best feasible design possible. In the later stage, shape and size optimization should be used to fine-tune the structure realized from the topology optimization and carried out physical experimentation to validate the model.
\end{abstract}

Keywords: Steering Yoke, Structural optimization, CATIA V5, Hyperworks

\section{INTRODUCTION}

The purpose of a steering system is to control the direction of the vehicle by operating the steering wheel of the steering system. Movement of steering wheel by the driver should cause an accurate response of the road wheels. The intermediate shaft connects the steering shaft to the steering pinion. These components cannot be arranged on the same axis due to the vehicle design limitations. They are arranged with the universal joints [1]. Control of vehicle should be maintained with safety throughout the speed range with little effort and over a wide range of road surfaces under all conditions [2-3].

The subassembly of steering yoke associated with this project work consists of two forged-steel yokes or forks joined to the two shafts being coupled and situated at right angles to each other. Steering Yoke would be the topic of interest for this case-study. A spider hinges these two yokes together. Since the arms of the spider are at right angles [4]. Topology optimization is a powerful structural optimization method that combines a numerical solution method, usually the finite element method, with an optimization algorithm to find the optimal material distribution inside a given domain. The purpose of topology optimization is to get the design that would be obtained on a uniformly fine mesh, but at a much lower computational cost by reducing the total number of elements and having fine elements only where and when necessary [5-6].
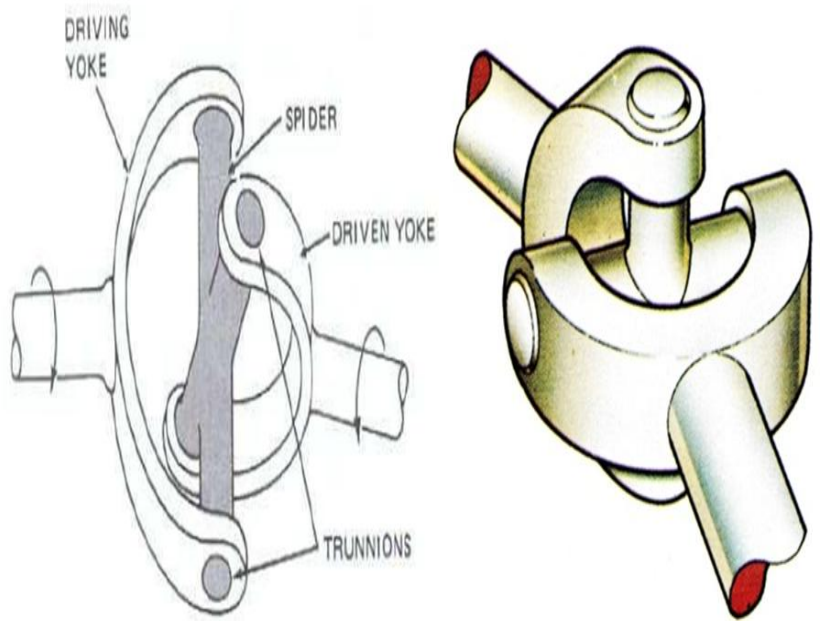

Fig 1: Cross Type Universal Joint

For modeling of the steering yoke, CATIA V5 R17 software is used. In the last decade the use of commercial optimization software for topology and shape optimization in the industry has increased rapidly and has shown to be applicable to many different types of problems. The idea is that the designer and the structural engineer both are involved in the initial stage 
when the first design proposal is conceived. Topology optimization is used to generate a good design concept [5]. Using this software, we can identify the nature and characteristics of stresses acting on the steering yoke. Figure shows the 3D model geometry of steering yoke assembly

The software that will be used are the preprocessor Hyper Mesh, the optimization tool Optistruct and the postprocessor Hyper View, all of them products of Altair Engineering.

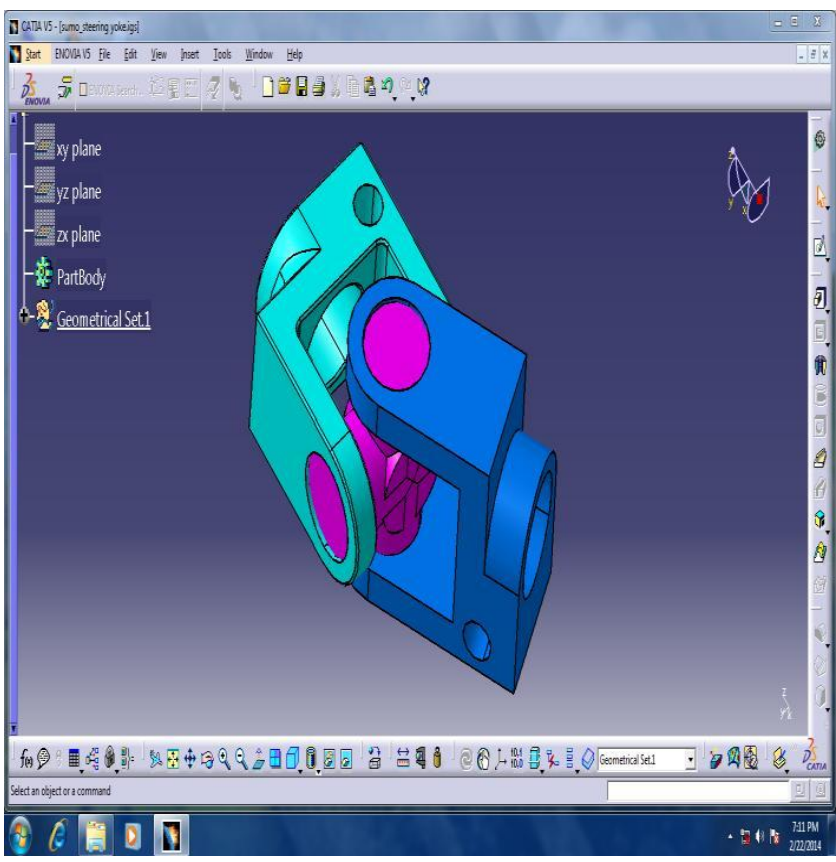

Fig 2: 3D Geometry Steering Yoke assembly

\section{OBJECTIVE}

The main aim of the project is to determine the Von Misses stresses, Element density distribution and Optimization in the existing Steering yoke.

Structural optimization is one application of optimization. Here the purpose is to find the optimal material distribution according to some given demands of a structure. Some common functions to minimize are the mass, displacement or the compliance (strain energy).

This problem is most often subject to some constraints, for example constraints on the mass or on the size of the component. This optimization is traditionally done manually using an iterative intuitive process that roughly consists of the following 3 steps:

1. A design is suggested

2. The requirements of the design is evaluated, for example by a finite element analysis (FEA)

3 . If the requirements are fulfilled, the optimization process is finished. Else, modifications are made, a new improved design is proposed and step 2-3 are repeated.

\section{GENERIC SPECIFICATIONS FOR A}

\section{STEERING YOKE}

- Material used: - Rolled/ Forged Steel - Carbon Steel

- C1021 or suitable

- Heat Treatment - Annealed.

- $\quad$ Typical hardness of the material - HRC 35-48

- Application for case study -Automobile (Steering yoke)

Table 1: Mechanical properties of C-1021 Steel

\begin{tabular}{|l|l|}
\hline Properties & Value \\
\hline Tensile strength, (MPa) & 420 \\
\hline Yield strength $(\mathrm{MPa})$ & 230 \\
\hline Youngs modulus, E (GPa) & 205 \\
\hline Elongation $(\%)$ & $24 \%$ \\
\hline Reduction in area (\%) & $48 \%$ \\
\hline
\end{tabular}

4. RESULT OF FINITE ELEMENT ANALYSIS AND COMPARISION WITH EXISTING RESULTS

By using hyper works software there are three steps. 1. Preprocessing, 2.processing (or) solution, 3.Post- processing.

\subsection{Pre-processing}

After modeling the component and importing to hypermesh window meshing is carried out.

\section{Meshing details-}

Number of elements $=27997$

Number of nodes $=28647$ Element size $=2.5$

Mesh type $=$ Second order Tetrahedral meshing

\subsection{Processing}

Boundary conditions - $350 \mathrm{Nm}$ torque applied at top of steering yoke.

Constraint given: - translation and rotational (1-6) at lower side.

\subsection{Post-Processing}

After successfully completed the process, the results can be viewed in hyper view. The three important results are noted and they are:

1. Vonmises elemental stress counter

2. Displacement counter

3. Mass counter

Firstly the component was designed for that vonmises elemental stress and displacement results are obtained from hyper works. 


\subsubsection{Vonmises Element Stress for Existing and Modified Yoke}

Following are Figures shows the optimized results along with the results of figures in reference paper and comparison for static analysis of steering yoke at torque $350 \mathrm{~N}-\mathrm{m}$.

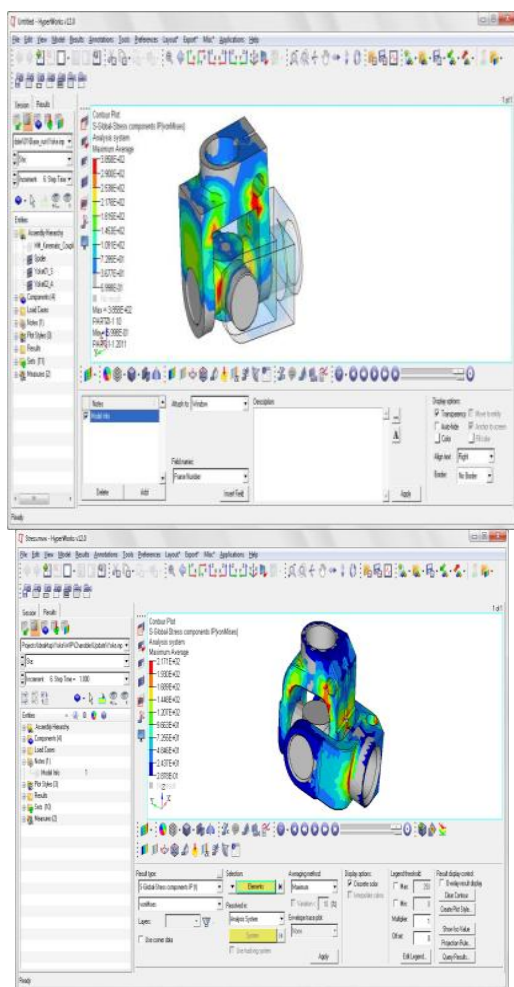

Fig 3: Von-Mises stresses contour for existing and modified steering yoke

\subsubsection{Displacement Counter for Existing and}

\section{Modified Steering Yoke}

Following are Figures shows the optimized results along with the results of figures in reference paper.

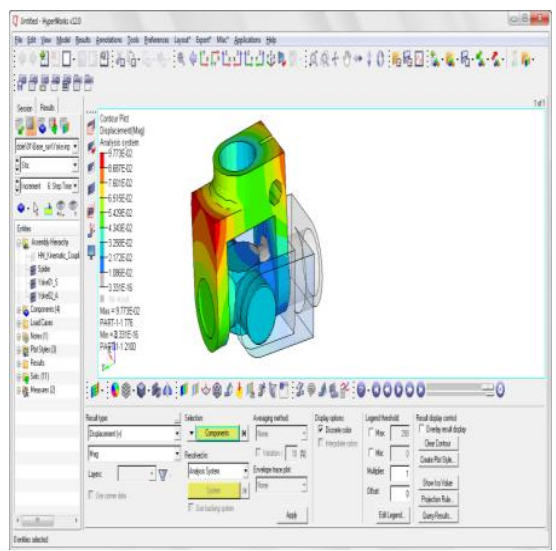

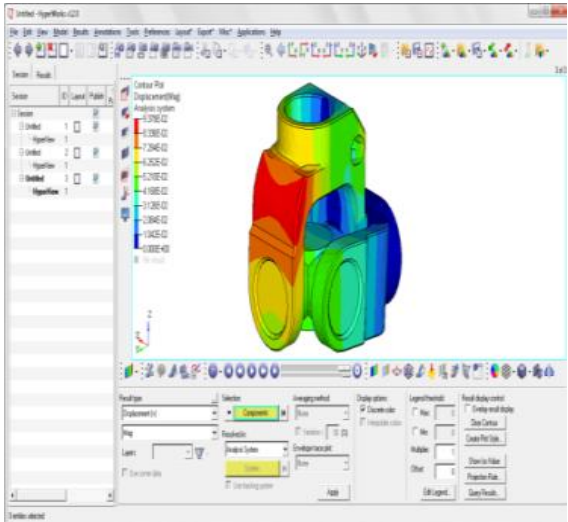

Fig 4: Displacement contour for existing and modified steering yoke

\subsubsection{Mass Counter for Existing and Modified Steering Yoke}

Following are Figures shows the optimized results along with the results of figures in reference paper.

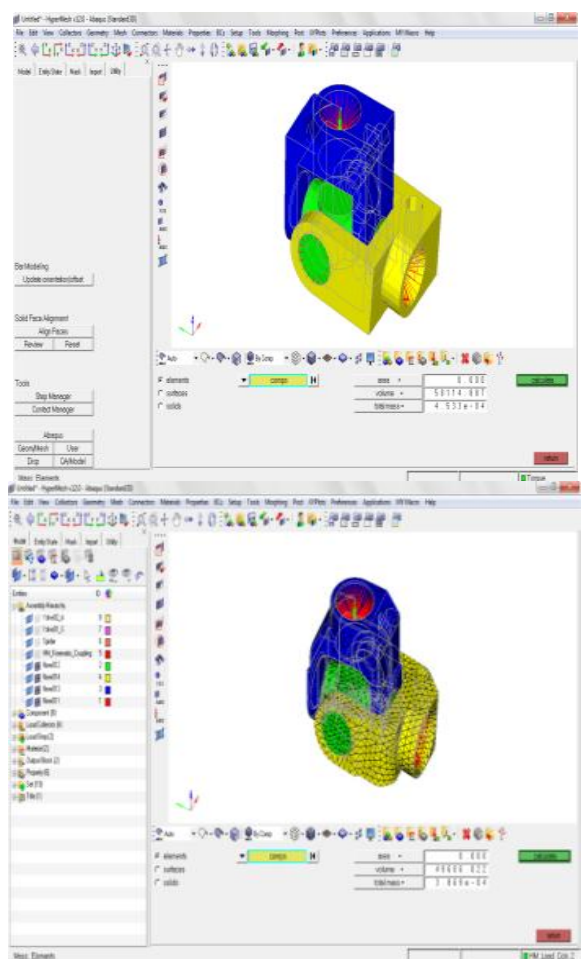

Fig 5: Mass contour for existing and modified steering yoke

\section{EXPERIMENTAL SETUP}

The objective of current work is to determine the stresses and displacement acting on the steering yoke by using Universal Testing Machine (UTM). After calculating the maximum stress value this value is compared with software values calculated by using Von-misses theory. Design of steering yoke by theoretical approach is very tough job because of its complicated structure and subjected to combined loads. Stresses which produced in Steering yoke assembly find out by experimentally using strain gauge technique which carried out. 


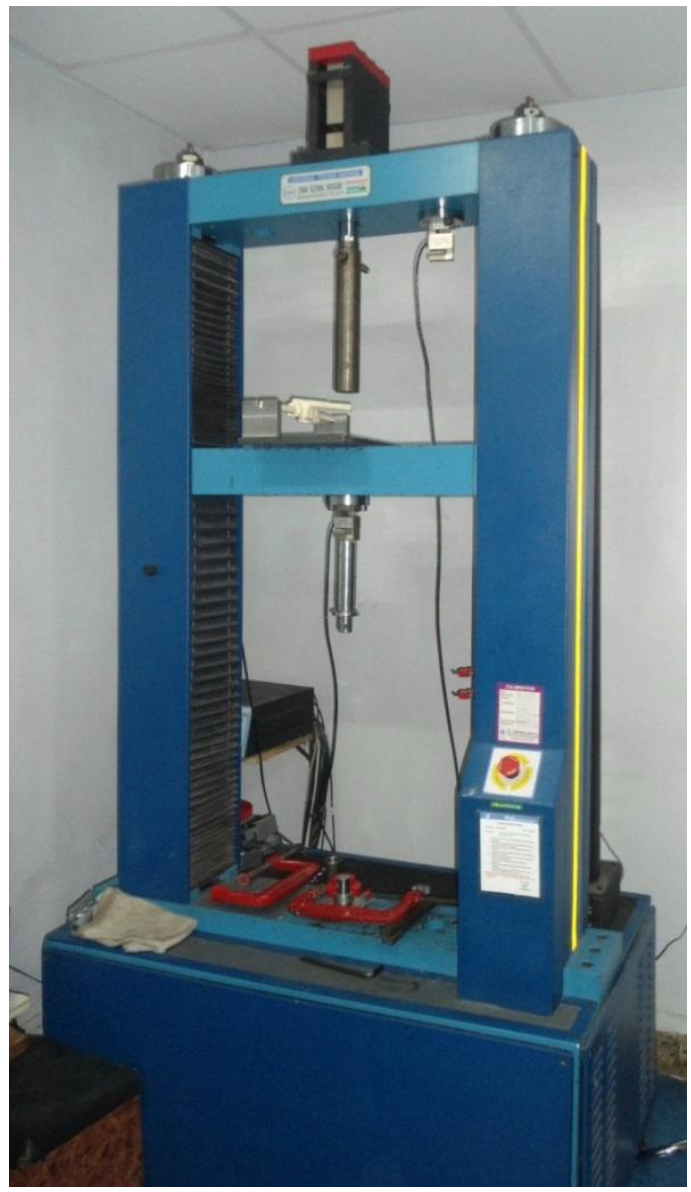

Fig 6: Universal Testing Machine (UTM)

Table 2: Readings and calculations

\begin{tabular}{|l|l|l|l|l|}
\hline $\begin{array}{l}\text { Load } \\
(\mathbf{F}) \\
(\mathbf{N})\end{array}$ & $\begin{array}{l}\text { Torque } \\
(\mathbf{T}) \\
(\mathbf{N}-\mathbf{m})\end{array}$ & $\begin{array}{l}\text { Strain } \\
\text { reading } \\
(\boldsymbol{\varepsilon}) \\
(\mathbf{m i c r o n s})\end{array}$ & $\begin{array}{l}\text { gauge } \\
\text { Strain } \\
(\mathbf{\varepsilon})\end{array}$ & $\begin{array}{l}\text { Stress } \\
(\boldsymbol{\sigma}) \\
\left(\mathbf{N} / \mathbf{m m}^{2}\right)\end{array}$ \\
\hline 66.67 & 10 & 32.6 & $0.3260 \times 10^{-4}$ & 6.68 \\
\hline 133.33 & 20 & 65.19 & $0.6519 \times 10^{-4}$ & 13.36 \\
\hline 200 & 30 & 97.79 & $0.9779 \times 10^{-4}$ & 20.04 \\
\hline 266.67 & 40 & 130.4 & $1.3040 \times 10^{-4}$ & 26.73 \\
\hline 2266.7 & 340 & 1109 & $1.1093 \times 10^{-3}$ & 230.5 \\
\hline 2333.4 & 350 & 1141 & $1.1414 \times 10^{-3}$ & 233.9 \\
\hline
\end{tabular}

\subsection{SAMPLE CALCULATIONS}

Calculation is done only last reading; the output voltage of Wheatstone bridge circuit $\left(\mathrm{V}_{\mathrm{o}}\right)$ will be equal to:

$$
V_{o}=\frac{V_{e x}}{4} \times(\text { gauge factor }) \times\left(\frac{\Delta L}{L}\right)
$$

Where,

$\mathrm{V}_{\mathrm{o}}=$ Output voltage of bridge

$\mathrm{V}_{\mathrm{ex}}=$ Input voltage of bridge

$\Delta \mathrm{L} / \mathrm{L}=\varepsilon=$ strain

Gauge factor for strain gauge $=2$
Using the above equation strain gauge reading, Strain $=\varepsilon=1141$ microns $=1.1414 \times 10^{-3} \mathrm{~mm}$.

Now by using Hooke's law,

Stress $=$ Young's modulus of elasticity x strain $\sigma=\mathrm{E} \times \varepsilon$

$=2.05 \times 10^{05} \times 1.1414 \times 10^{-3}$

$=233.98 \mathrm{~N} / \mathrm{mm}^{2}$

$=234 \mathrm{~N} / \mathrm{mm}^{2}$.

Experimental value

$\sigma=217 \mathrm{~N} / \mathrm{mm}^{2}$. Software value

\section{RESULTS}

Thus the steering yoke is analyzed by using hyper works software and the obtained results are compared with experimental results. Here the results obtained i.e. Stresses observed in modified yoke are greater than yield limit. There is no plastic straining and permanent set. Therefore the steering yoke is safe.

There is a fairly good agreement between the Experimental result and FEA/software result at stressed location of steering yoke.

Table 3: Comparison / Interpretation of the results

\begin{tabular}{|l|l|l|l|l|}
\hline Parameters & $\begin{array}{l}\text { Existing } \\
\text { yoke }\end{array}$ & $\begin{array}{l}\text { Modifie } \\
\text { d yoke }\end{array}$ & $\begin{array}{l}\text { Experim } \\
\text { ental } \\
\text { result }\end{array}$ & A \\
\hline $\begin{array}{l}\text { Torque (N- } \\
\text { m) }\end{array}$ & 350 & 350 & 350 & \\
\hline $\begin{array}{l}\text { Maximum } \\
\text { stress } \\
\left(\mathrm{N} / \mathrm{mm}^{2}\right)\end{array}$ & 386 & 217 & 234 & 7.83 \\
\hline $\begin{array}{l}\text { Displacemen } \\
\mathrm{t}(\mathrm{mm})\end{array}$ & $\begin{array}{l}9.773 \\
10^{-2}\end{array}$ & $\begin{array}{l}9.378 \\
10^{-2}\end{array}$ & & \\
\hline Mass (gram) & 450 & 386 & 395 & \\
\hline
\end{tabular}

$A$ = Percentage deviation of FEA/software value from Experimental value. 


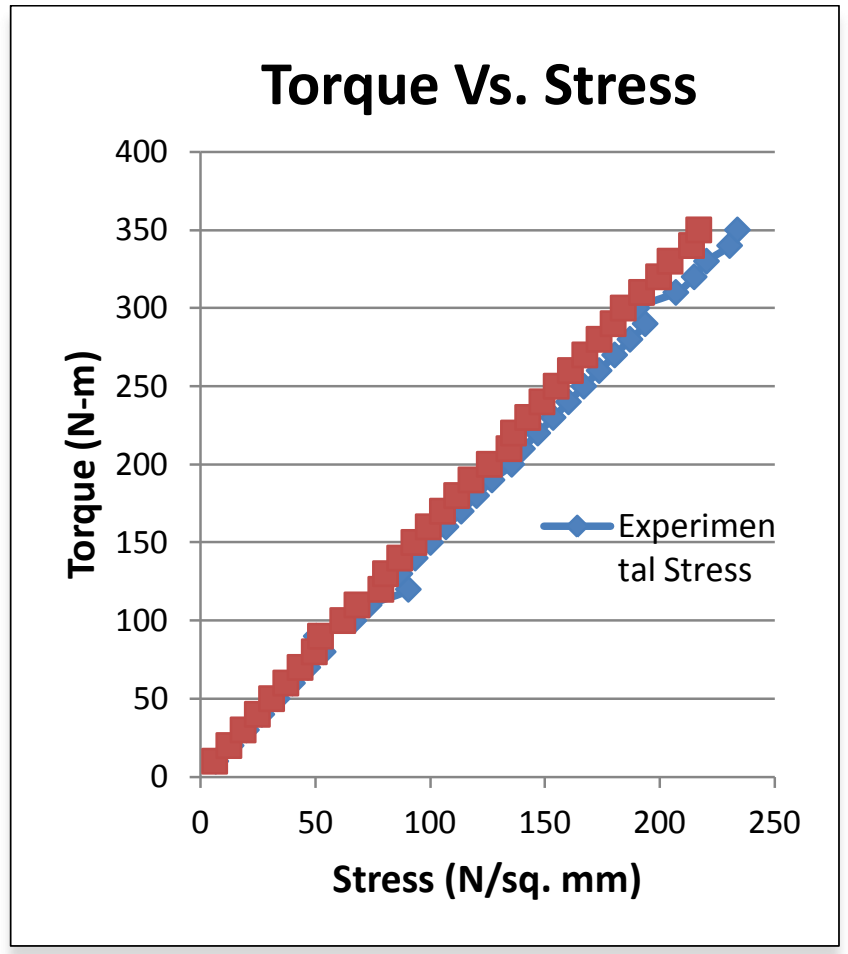

Fig 7: Comparison of Torque Vs. FEA and Experimental Stress

\section{CONCLUSION}

In this paper work the design and finite element analysis of steering yoke used in automobiles by HYPER MESH is carried out. The steering yoke is analyzed for the stress produced under torque load conditions. Experimental results are compared with FEA/software result. This work involves the comparison of existing yoke and modified yoke under static loading conditions. The conclusions from the results are as follows:

1. Steering yoke is analyzed under constant torque load $350 \mathrm{~N}$-m from steering column.

2. From the FEA/software result, the maximum stress observed in the modified steering yoke is 217 $\mathrm{N} / \mathrm{mm} 2$ and the material Yield stress value is 230 $\mathrm{N} / \mathrm{mm} 2$. Hence the design of modified steering yoke is safe.

3. The mass of modified yoke is reduced by $16.58 \%$ over existing/original steering yoke.

4. From the experimentation work it is observed that, the maximum stress in the modified steering yoke is $234 \mathrm{~N} / \mathrm{mm} 2$ and the material Yield stress value is $230 \mathrm{~N} / \mathrm{mm} 2$. Hence the design of modified steering yoke is safe.

5. Variation of $7.83 \%$ is observed in maximum stress among experimental values and FEA/software values.

\section{ACKNOWLEDGEMENTS}

The author special thanks for valuable guidance by Mechanical Engineering department of Late G. N. Sapkal College of Engineering, Anjneri, (Nasik).

\section{REFERENCES}

[1] S.Kinme, T.kamikawa and A.nishino "Development of stamped Yoke for high rigidity intermediate shaft" Technical report, Koya engineering journal English edition No. 165E (2004)

[2] Dr. Kirpal Singh, "Automobile Engineering" Volume 1, Standard publication publications, New Delhi, 2004, Page no.10-15.

[3] R. B. gupta, "Automobile engineering" 12th edition- 2009, Page No.538-539 \& 595-606.

[4] Mr. P.G. Thate and Prof. D.S. Bajaj, "Review on Failure Analysis of yoke assembly of a transmission drive shaft subjected to Torsion and Shear" IJERT, ISSN: 2278-0181 Volume-2, Issue10, October-2013.

[5] Mr. Anton olason and Daniel tidman, “ Methodology for Topology and Shape Optimization in the Design Process" ISSN 16528557, Department of Applied Mechanics, Chalmers University of Technology, Sweden.

[6] Eric DE STURLER, Glaucio H. PAULINO and Shun WANG, "Topology optimization with adaptive mesh refinement" Proceedings of the 6th International Conference on IASS-IACM 2008: "Spanning Nano to Mega" 28-31 May 2008, Cornell University, Ithaca, NY, USA.

\section{BIOGRAPHIES}

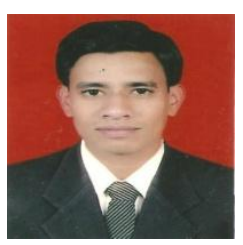

Santosh Kailas Chandole, Has completed ME in Design Engineering \& currently working as an Assistant Professor in Late G. N. Sapkal COE, Anjaneri, Dist:- Nasik., Maharashtra, India

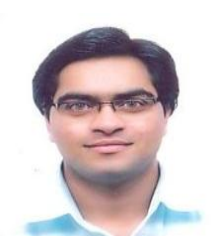

Mikhil Kailas Bhavsar, Pursuing ME in Design Engineering at Amrutvahini COE Sangamner, Dist: - Ahmednagar, Maharashtra, India

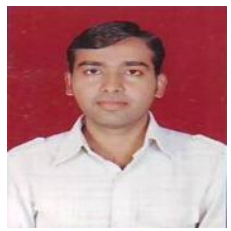

Santosh Saheberao Sarode, Has completed ME in Design Engineering \& currently working as an Assistant Professor in Late G. N. Sapkal COE, Anjaneri, Dist:- Nasik, Maharashtra, India

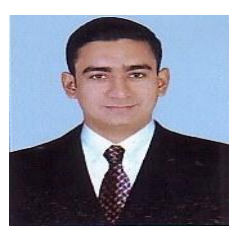

Gokul Ramdas Jadhav, Pursuing ME in Design Engineering at Late G. N. Sapkal COE, Anjaneri, Dist:- Nasik., Maharashtra, India 